\title{
Embryotoxicity of regressing corpora lutea in ewes
}

\author{
B. A. Costine, B. L. Sayre* and E. K. Inskeep ${ }^{\dagger}$ \\ Division of Animal and Veterinary Sciences, West Virginia University, \\ Morgantown, WV 26506-6108, USA
}

\begin{abstract}
Experiments were performed to test the null hypotheses that embryonic survival is not affected by the presence of regressing corpora lutea in progestogen-supplemented ewes, and that the embryotoxic effects of regressing corpora lutea do not act locally on embryos in the uterine horn adjacent to the regressing corpora lutea. In Expt 1, laparotomies were performed on day 4 after mating, and progestogen supplementation was initiated and continued until pregnancy was diagnosed by ultrasonography on day 25. On day 4 after mating, ewes were lutectomized $(n=17)$ or sham lutectomized $(n=15)$, and injected (i.m.) with 5 mg PGF PG $_{2 \alpha}$ at 8 intervals for 2 or 3 days. Controls $(n=14)$ were sham lutectomized and injected with saline as described above. Pregnancy rates did not differ in ewes treated with $\mathrm{PGF}_{2 \alpha}$ for 2 rather than 3 days. Pregnancy rates were lower in ewes treated with $\mathrm{PGF}_{2 \alpha}$ compared with controls $(P<0.01)$. In ewes treated with $\mathbf{P G F}_{2 \alpha}$ lutectomy resulted in an increase in pregnancy rates $(59 \%)$
\end{abstract}

compared with ewes subjected to sham lutectomy (33\%; $P<0.05)$. In Expt 2, progestogen supplementation was initiated in the morning of day 4 after mating and continued until pregnancy diagnosis on day 25 . In the afternoon of day 4 , one ovary selected at random was lutectomized in ewes $(n=34)$ with at least one corpus luteum on each ovary, and the uterine horns were isolated by ligation to impede intraluminal transfer of luteal or uterine products that might initiate embryonic death. On days 5-8 after mating, equal numbers of ewes were injected i.m. with either saline or $5 \mathrm{mg} \mathrm{PGF}_{2 \alpha}$ at $8 \mathrm{~h}$ intervals. Pregnancy rates did not differ between isolated uterine horns contralateral and ipsilateral to the regressing corpus luteum; however, pregnancy rates were lower in $\mathrm{PGF}_{2 \alpha}$-treated ewes than in saline-treated ewes (34 and $77 \% ; P<0.05)$. In conclusion, regressing corpora lutea exert an embryotoxic effect; however, there is no evidence that this effect occurs through systemic pathways.

\section{Introduction}

The corpus luteum produces progesterone, which is required for the maintenance of pregnancy. The first ovulation that occurs after reproductive quiescence in ruminants yields a corpus luteum that regresses before maternal recognition of pregnancy (Cooper et al., 1991), resulting in low fertility (Casida et al., 1968; RamirezGodinez et al., 1982). Progestogen supplementation is an obvious strategy to support pregnancy in cases of an early regressing corpus luteum. However, progesterone supplementation in cows inseminated at the first postpartum oestrus did not prevent embryonic death (Wiltbank et al., 1956; Breuel et al., 1993) unless it was accompanied by both treatment with a prostaglandin synthesis inhibitor and removal of the regressing corpus luteum (Buford et al., 1996). Buford et al. (1996) treated progestogensupplemented, non-lactating cows with $\mathrm{PGF}_{2 \alpha}$ at $8 \mathrm{~h}$ intervals on days 5-8 after oestrus. Treatment with $\mathrm{PGF}_{2 \alpha}$ results in lower pregnancy rates in cows that had an intact corpus lutuem compared with saline-treated cows (20 versus $71 \%$ ) but pregnancy rates in $\mathrm{PGF}_{2 \alpha}$-treated cows

*Present address: Virginia Cooperative Extension, Small Ruminant Program, Virginia State University, Petersburg, VA 23806, USA ${ }^{+}$Correspondence

Email: einskeep@wvu.edu were higher $(80 \%)$ if the corpus luteum was removed on day 5 after oestrus. These data led to the suggestion that luteal regression during days 4-8 after mating had an embryotoxic effect (Buford et al., 1996).

Little is known about the mechanism by which the early regressing corpus luteum causes embryonic death. Substances from the ovary could reach the uterus via systemic circulation. In addition, the anatomical structure of the ruminant reproductive tract allows an ovary to have localized effects on the adjacent uterine horn (Ginther and Del Campo, 1973). The oviductal vein delivers progesterone from the ovary directly to the cranial portion of the adjacent uterine horn (Weems et al., 1989). Likewise, during normal luteal regression, $\mathrm{PGF}_{2 \alpha}$ synthesized by the uterus is transferred from the blood and lymph vessels of the uterus directly to the ovarian artery by slow diffusion, bypassing the systemic circulation in which two-thirds of $\mathrm{PGF}_{2 \alpha}$ is inactivated after one passage through the lungs of ruminants (Bonnin et al., 1999). Products of early luteal regression that cause embryonic death could reach the embryo via the systemic circulation, local utero-ovarian circulation or local lymphatic circulation.

Hernandez-Fonseca et al. (2000) used embryo transfer to test for local embryotoxic effects of regressing corpora lutea in progestogen-supplemented cows treated with saline or $\mathrm{PGF}_{2 \alpha}$ at $8 \mathrm{~h}$ intervals on days $5-8$ after oestrus. An embryo 
was transferred into each uterine horn, ipsilateral and contralateral to the corpus luteum. Treatment with $\mathrm{PGF}_{2 \alpha}$ reduced pregnancy rates in ewes $\left(\mathrm{PGF}_{2 \alpha} 33 \%\right.$ versus saline $77 \%$ ), but there was no evidence of a local relationship. The approach used by Hernandez-Fonseca et al. (2000) did not rule out the luminal flow of embryotoxic products between uterine horns. Elucidation of the local effect of the embryo to maintain the corpus luteum of pregnancy required isolation of the uterine horns by ligation (Moor and Rowson, 1966). Although the embryotoxic effect involves an effect of the ovary on the uterus, rather than an effect of the uterus or its contents on the ovary, flow of uterine luminal contents between uterine horns may contribute to the embryotoxic effect.

The present study tested the null hypotheses that embryonic survival is not affected by the presence of a regressing corpus luteum in progestogen-supplemented ewes, and that the embryotoxic effects of the regressing corpus luteum do not act locally on embryos in the uterine horn adjacent to the regressing corpus luteum.

\section{Materials and Methods}

\section{Animals}

All protocols were approved by the Animal Care and Use Committee (West Virginia University, Morgantown, WV). Ewes (Ovis aries) of mixed breeding, mainly Dorset and Suffolk, were housed in an open pole barn until surgery, and were tested each day for oestrus using a vasectomized ram. At days 5-10 after oestrus, groups of ewes $(n=8-12$ per group) were treated with two i.m. injections of $5 \mathrm{mg}$ PGF $_{2 \alpha}$ (Lutalyse ${ }^{\circledR}$; Pharmacia Inc., Kalamazoo, MI) at $4 \mathrm{~h}$ intervals to synchronize oestrus (Hawk, 1973). Ewes were observed for signs of oestrus at $12 \mathrm{~h}$ intervals, and ewes showing signs of oestrus were mated with two fertile rams.

\section{Experiment 1}

An intravaginal sponge containing $60 \mathrm{mg}$ progestogen flurogestone acetate (G. D. Searle \& Co., Chicago, IL) was inserted into ewes $(n=60)$ on day 4 after oestrus and was removed after diagnosis of pregnancy on day 25 . On the afternoon of day 4, ewes were anaesthetized with sodium pentobarbital (Sigma, St Louis, MO) administered i.v. and a mid-ventral laparotomy was performed to expose the reproductive tract. Ewes were either sham lutectomized (ovary observed and handled) and injected i.m. with PGF $2 \alpha$ $(n=15)$ or saline $(n=14)$ at $8 \mathrm{~h}$ intervals for $2(n=16)$ or 3 $(n=13)$ days, or were lutectomized and injected with $\mathrm{PGF}_{2 \alpha}(n=17$; Fig. 1$)$ at $8 \mathrm{~h}$ intervals for $2(n=7)$ or 3 $(n=10)$ days. Treatment for 2 or 3 days was tested because it was not known whether treatments that were effective in cattle would be effective in sheep or the duration of treatment that was required. Pregnancy was determined by transrectal ultrasonography (Schrick et al., 1993) using an Aloka 500 console (Aloka Co. Ltd, Wallingford, CT) fitted with a $7.5 \mathrm{MHz}$ transducer.

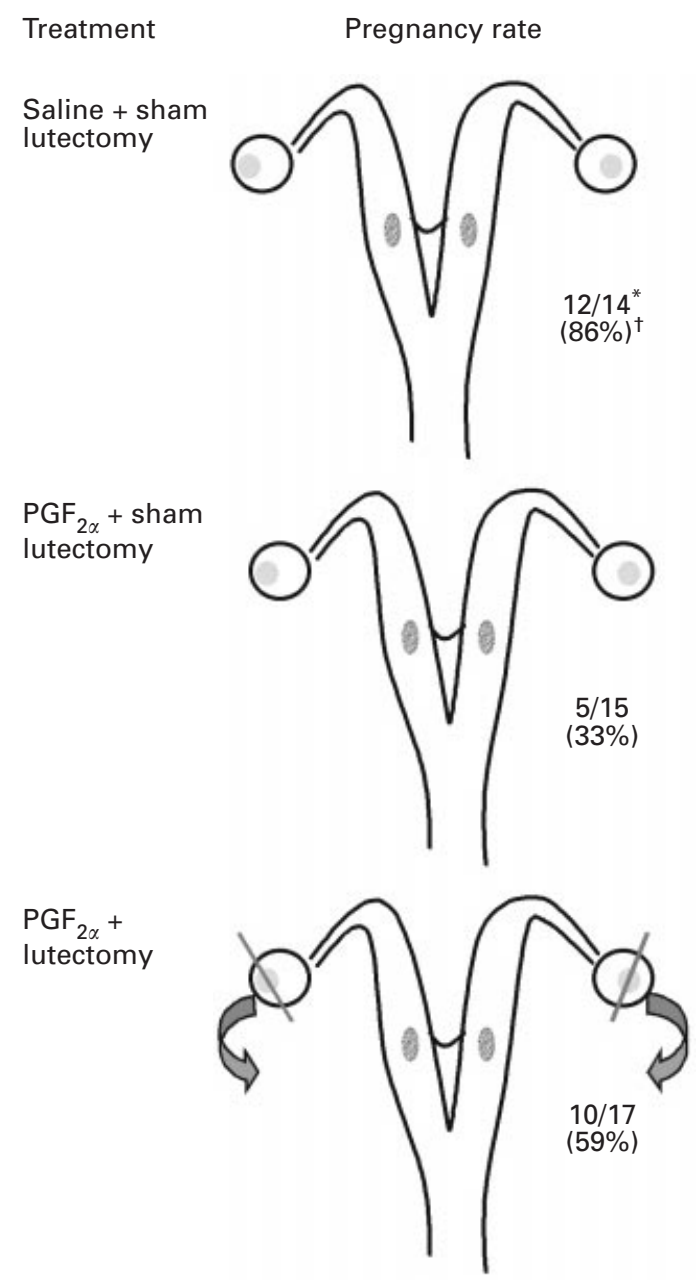

Fig. 1. The effects of treatment with $5 \mathrm{mg} \mathrm{PGF}{ }_{2 \alpha}$ (at $8 \mathrm{~h}$ intervals for 2 or 3 days) and either lutectomy or sham lutectomy, or treatment with saline (at $8 \mathrm{~h}$ intervals for 2 or 3 days) and sham lutectomy on pregnancy rates at day 25 in progestogen-supplemented ewes (Expt 1). *Number of ewes pregnant per number of ewes treated. tPercentage of ewes that are pregnant. Treatment with $\mathrm{PGF}_{2 \alpha}$ resulted in a lower pregnancy rate $(P<0.01)$. Lutectomy of ewes treated with $\mathrm{PGF}_{2 \alpha}$ increased pregnancy rate $(P<0.05)$.

\section{Experiment 2}

Ovaries were observed for the presence of young corpora lutea by transrectal ultrasonography on the morning of day 4 after mating. In the afternoon of day 4, ewes that appeared to have at least one corpus luteum on each ovary $(n=70)$ were anaesthetized with sodium pentobarbital and a mid-ventral laparotomy was performed to expose the reproductive tract. Because of the difficulty in distinguishing a corpus albicans from a day 4 corpus luteum using ultrasonography, only $49 \%$ of the ewes that were laparotomized actually had at least one corpus luteum on each ovary and were used in the experiment $(n=34)$. One ovary was selected at random, and the corpus luteum, including connective tissue encapsulating the corpus 
luteum, was removed by digital pressure. From the morning of day 4 to day 25, ewes were injected s.c. at $12 \mathrm{~h}$ intervals with $25 \mathrm{mg}$ progesterone (Sigma) in corn oil.

Each uterine horn was ligated with a single ligature placed cranial to the internal bifurcation and caudal to the external bifurcation, isolating the uterine horns from the uterine body (Fig. 2). On the mesometrial side of the uterus, the suture was passed beneath the perimetrium and around the myometrium of the horn, thereby avoiding the mesenteric ligaments and major vasculature (Moor and Rowson, 1966). The ligature was anchored by suturing through the perimetrium on the antimesometrial side of the uterus. In two individual ewes, one uterine horn was injected with $5 \mathrm{ml}$ India ink after ligation, and the reproductive tract was examined 1 week after surgery. The ink did not pass the ligatures in either of the ewes.

From the morning of day 5 after oestrus, ewes were assigned at random to receive either $5 \mathrm{mg} \operatorname{PGF}_{2 \alpha}(n=19)$ or saline $(n=15)$ at $8 \mathrm{~h}$ intervals for 3 days. Each uterine horn was examined by transrectal ultrasonography on day 25 for the presence of an embryo with a heartbeat. If ultrasonography revealed the presence of fluid and membranes without an apparent embryo, ewes were killed and the reproductive tracts were examined for the presence of an embryo.

\section{Statistical analysis}

In Expt 1, differences in pregnancy rates due to treatment for 2 versus 3 days with either saline or $\mathrm{PGF}_{2 \alpha}$, treatment with saline versus $\mathrm{PGF}_{2 \alpha}$, and pregnancy rates in PGF-treated ewes that were sham lutectomized versus lutectomized were tested using the chi-squared test with the CATMOD procedure of SAS (1995). The effects of the location of the embryo with respect to the regressing corpus luteum (ipsilateral versus contralateral), and treatment by location interaction on pregnancy rates in Expt 2 were examined in the same manner.

\section{Results}

\section{Experiment 1}

The percentages of ewes pregnant after treatment with $\mathrm{PGF}_{2 \alpha}$ for 2 rather than 3 days did not differ and the data were pooled for the duration of treatment. Treatment with $\mathrm{PGF}_{2 \alpha}$ resulted in a lower pregnancy rate than in controls $(P$ $<0.01$; Fig. 1). In ewes treated with $\mathrm{PGF}_{2 \alpha}$, lutectomy resulted in an increase in pregnancy rates (59\%) compared with sham lutectomy $(33 \% ; P<0.05)$.

\section{Experiment 2}

In saline-treated ewes, embryos were present in $77 \%$ of uterine horns, but treatment with $\mathrm{PGF}_{2 \alpha}$ reduced the percentage of embryos in uterine horns to $34 \%(P<0.05$; Fig. 2). However, the ability of the embryo to survive was not affected by the location of the embryo with respect to the corpus luteum (uterine horn and treatment $\times$ uterine horn, not significant).

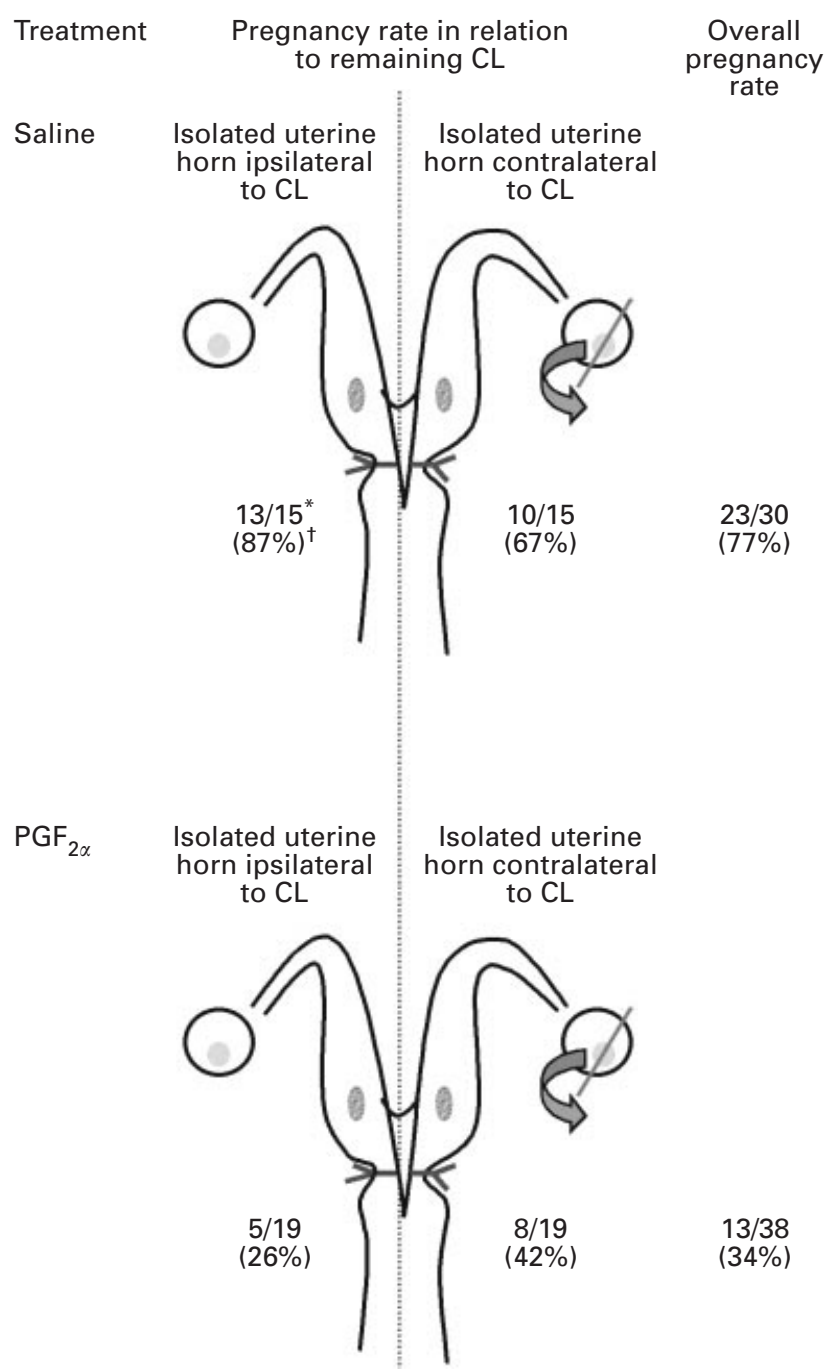

Fig. 2. The effect of embryo location in relation to the location of the remaining corpus luteum $(\mathrm{CL})$ on pregnancy rates at day 25 in bilaterally ovulating progestogen-supplemented ewes that were treated with saline or $5 \mathrm{mg} \mathrm{PGF}{ }_{2 \alpha}$ (at $8 \mathrm{~h}$ intervals on days 5-8) in Expt 2. ${ }^{*}$ Number of uterine horns containing an embryo per number of uterine horns treated. 'Percentage of uterine horns containing an embryo. There was a main effect of treatment $(P<0.05)$ and no effect of uterine horn or treatment $\times$ uterine horn.

In three of the ewes treated with $\mathrm{PGF}_{2 \alpha}$, membranes and fluid were observed in a uterine horn during ultrasonography on day 25, but embryonic heartbeats were not recorded in these uterine horns. In two of these ewes, fluid and membranes were present in both uterine horns, and in one ewe, fluid and membranes were present in the contralateral horn only. In a fourth ewe treated with $\mathrm{PGF}_{2 \alpha^{\prime}}$ an embryonic heartbeat was recorded in one uterine horn, and membranes and fluid were observed in the other uterine horn. Examination of the reproductive tracts after the ewes had been killed revealed that fluid and membranes were present in the uterine horns of three ewes as indicated by ultrasonography, but embryos were not present. In the 
fourth ewe, an embryo was present in the uterine horn ipsilateral to the regressing corpus luteum, and membranes and fluid were present in the contralateral horn. These observations confirmed the ultrasonographic data and these ewes were included in the analysis.

\section{Discussion}

Chronic treatment of ewes with $\mathrm{PGF}_{2 \alpha}$ reduced embryonic survival despite progestogen replacement therapy. In Expt 1 , pregnancy rates in ewes treated with $\mathrm{PGF}_{2 \alpha}$ were higher in ewes that were lutectomized than in ewes that were sham lutectomized. This result is consistent with those reported in cows. Treatment of progestogen-supplemented cows with $\mathrm{PGF}_{2 \alpha}$ at $8 \mathrm{~h}$ intervals on days 5-8 after mating resulted in a decrease in embryonic survival compared with cows treated with saline (25 versus 67\%, Buford et al., 1996; 23 versus $71 \%$, Seals et al., 1998).

An early regressing corpus luteum affects embryos in a stage-specific manner. In vivo, stage specificity is emphasized by the fact that embryonic survival is reduced when progestogen-supplemented cows are treated with $\mathrm{PGF}_{2 \alpha}$ on days $4-7$ or days 5-8 after mating, but not on days 10-13 or days 15-18 after mating (Seals et al., 1998). The embryo develops from a morula to a blastocyst on days 4-5 of pregnancy, hatches from the zona pellucida on days 7-9 and elongates on days 12-13 (Rowson and Moor, 1966). From these results, it can be concluded that embryos are susceptible during the morula and blastocyst stages, but not during the periods of elongation or maternal recognition of pregnancy, or that the embryotoxic mechanism is no longer functional after day 10 of pregnancy.

Direct embryotoxicity of $\mathrm{PGF}_{2 \alpha}$ is supported by in vitro experiments; however, the stage at which treatment with PGF $_{2 \alpha}$ arrested embryonic development differed between in vitro and in vivo conditions. Incubation of bovine embryos at the morula stage with $\mathrm{PGF}_{2 \alpha}$ did not affect the percentage of embryos reaching the early blastocycst stage, but it decreased the percentage of embryos that developed to hatched and expanded blastocysts (43\% treated versus $77 \%$ control; Fazio et al., 1997). Treatment with $\mathrm{PGF}_{2 \alpha}$ in vivo on days 5-8 reduced the percentage of embryos collected on day 8 from progestogen-supplemented cows that reached the early blastocyst stage $(36 \%$ treated versus $100 \%$ controls; Hockett et al., 1998). Incubation of rat embryos with $\mathrm{PGF}_{2 \alpha}$ and luteal tissue delayed embryonic development more than did incubation with $\mathrm{PGF}_{2 \alpha}$ alone (Buuck, 1997). These data support the concept that the early regressing corpus luteum is required for the full embryotoxic effect of $\mathrm{PGF}_{2 \alpha}$. Indeed, reduction of prostaglandin production alone was not sufficient to improve pregnancy rates in postpartum cows with early regressing corpora lutea that were supplemented with progestogen (Buford et al., 1996).

The corpus luteum could be a significant source of $\mathrm{PGF}_{2 \alpha}$ in ewes or cows with an early regressing corpus luteum. Short-lived corpora lutea produced higher concentrations of
$\mathrm{PGF}_{2 \alpha}$ in vitro than did corpora lutea expected to have a normal lifespan (Hu et al., 1990). Although the ability of the corpus luteum to synthesize prostaglandin early in the oestrous cycle is lower than that of corpus luteum in midcycle after a single injection of PGF $_{2 \alpha}$ (Tsai and Wiltbank, 1998), the prostaglandin synthetic enzymes, prostaglandin $\mathrm{H}$ synthase-2 (also known as Cox-2) and PGF synthase, were upregulated in the early corpus luteum after chronic treatment with $\mathrm{PGF}_{2 \alpha}$ (Sayre et al., 2000). PGF $2 \alpha$ produced by the corpus luteum may be an important part of luteal regression at the end of the oestrous cycle, amplifying the effect of PGF ${ }_{2 \alpha}$ from the uterus (Tsai and Wiltbank, 1997).

In Expt 2, embryonic survival did not differ in isolated uterine horns contralateral and ipsilateral to the regressing corpus luteum. Thus, the products of early luteal regression that caused embryonic death, despite progestogen supplementation, could not be shown to reach the embryo by local pathways. These results extend those of HernandezFonseca et al. (2000), who did not find a difference in the rate of embryonic survival when embryos were transferred into the uterine horn ipsilateral or contralateral to the ovary bearing the early regressing corpus luteum in progestogensupplemented cows. To date, there is no evidence of a local effect in either species.

The apparent systemic effect of the early regressing corpus luteum is in contrast to the local effects of the nonpregnant (Inskeep and Butcher, 1966) or pregnant (Moor and Rowson, 1966) uterus on the adjacent corpus luteum. The early regressing corpus luteum might systemically kill susceptible embryos (on days 5-8) by any of three scenarios: (i) an unknown factor secreted from the regressing corpus luteum might have a long half-life and circulate systemically; (ii) the portion of $\mathrm{PGF}_{2 \alpha}$ that is circulating systemically might differ during early luteal regression compared with normal luteal regression; or (iii) the systemic effect of an early regressing corpus luteum might be due to a lower threshold for $\mathrm{PGF}_{2 \alpha}$ to cause embryonic death directly or to initiate the production of embryotoxins in the uterus compared with the amount of $\mathrm{PGF}_{2 \alpha}$ required to cause luteal regression.

Oxytocin, which is secreted from luteal cells exposed to PGF $_{2 \alpha^{\prime}}$ has been implicated as a possible component of the embryotoxic effect (Lemaster et al., 1999). Oxytocin has a half-life of 3-5 min (Fabian et al., 1969). Luteal oxytocin is thought to be part of a positive feedback system between the uterus and the corpus luteum during luteal regression, stimulating further production of $\mathrm{PGF}_{2 \alpha}$ by the uterus. In progestogen-supplemented cows treated with $\mathrm{PGF}_{2 \alpha}$ at $8 \mathrm{~h}$ intervals on days 5-8 after oestrus, concentrations of oxytocin were greater 30 min after treatment in intact cows than they were in lutectomized cows (Buford et al., 1996; Seals et al., 1998). Reduced pregnancy rates in progestogensupplemented cows treated with oxytocin at $8 \mathrm{~h}$ intervals on days $5-8(33 \%)$ were restored to control values $(80 \%)$ if oxytocin-treated cows were treated concomitantly with a prostaglandin synthesis inhibitor (Lemaster et al., 1999). Lutectomy did not increase pregnancy rates in oxytocin- 
treated cows. On the basis of these data, the embryotoxic effect of an early regressing corpus luteum may result, at least in part, from stimulation of uterine secretion of $\mathrm{PGF}_{2 \alpha}$ by luteal oxytocin.

An early regressing corpus luteum had an embryotoxic effect despite progestogen supplementation in ewes, as in cows. Although the maternal recognition of pregnancy and normal luteal regression are locally mediated events, the early regressing corpus luteum in progestogen-supplemented ewes appears to kill embryos systemically. The mechanisms involved in embryonic death caused by short luteal phases might be applicable to situations in which the incidence of embryonic death is high, but the corpus luteum is not completely regressed.

The authors would like to thank Pharmacia Inc. for the generous gift of Lutalyse. B. A. Costine was the recipient of a National Wool Growers Memorial Fellowship. This manuscript has been published with the approval of the director of the West Virginia Agricultural and Forestry Experiment Station as Scientific Paper No. 2793 Supported by Hatch 321 (NE 161).

\section{References}

Bonnin P, Huynh L, L'Haridon R, Chene N and Martal J (1999) Transport of uterine $\mathrm{PGF}_{2 \alpha}$ to the ovaries by systemic circulation and local lymphovenous-arterial diffusion during luteolysis in sheep Journal of Reproduction and Fertility 116 199-210

Breuel KF, Lewis PE, Schrick FN, Lishman AW, Inskeep EK and Butcher RL (1993) Factors affecting fertility in the postpartum cow: role of the oocyte and follicle in conception rate Biology of Reproduction $\mathbf{4 8}$ 655-661

Buford WI, Ahmad N, Schrick FN, Butcher RL, Lewis PE and Inskeep EK (1996) Embryotoxicity of a regressing corpus luteum in beef cows supplemented with progestogen Biology of Reproduction 54 531-537

Buuck MJ (1997) Effects of Prostaglandin $F_{2 \alpha}$ on In Vitro and In Vivo Development of Preimplantation Rat Embryos MS Thesis, University of Tennessee, Knoxville

Casida LE, Graves WE, Lauderdale JW, Riesen JW, Saiduddin S, Hauser ER and Tyler WJ (1968) Studies on the postpartum cow Research Bulletin, The University of Wisconsin 270 1-54

Cooper DA, Carver DA, Villeneuve P, Silvia WJ and Inskeep EK (1991) Effects of progestagen treatment on concentrations of prostaglandins and oxytocin in plasma from the posterior vena cava of post-partum beef cows Journal of Reproduction and Fertility 91 411-421

Fabian M, Forsling ML, Jones JJ and Pryor JS (1969) The clearance and antidiuretic potency of neurohypophysial hormones in man, and their plasma binding and stability Journal of Physiology 204 653-678

Fazio RA, Buuck MJ and Schrick FN (1997) Embryonic development of frozen-thawed bovine embryos cultured in vitro in response to elevated concentrations of prostaglandin $\mathrm{F}_{2 \alpha}$ Biology of Reproduction $\mathbf{5 6}$ (Supplement 1) 187 (Abstract)

Ginther OJ and Del Campo CH (1973) Vascular anatomy of the uterus and ovaries and the unilateral luteolytic effect of the uterus: areas of close apposition between the ovarian artery and vessels which contain uterine venous blood in sheep American Journal of Veterinary Research 34 1387-1393

Hawk HW (1973) Uterine motility and sperm transport in the estrous ewe after prostaglandin induced regression of corpora lutea Journal of Animal Science 37 1380-1385

Hernandez-Fonseca HJ, Sayre BL, Butcher RL and Inskeep EK (2000) Embryotoxic effects adjacent and opposite to the short-lived bovine corpus luteum Theriogenology 54 83-91

Hockett ME, Rohrbach NR and Schrick FN (1998) Effect of administration of $\mathrm{PGF}_{2 \alpha}$ on embryonic development and quality in cows supplemented with exogenous progestogen Journal of Animal Science 76 (Supplement 1) 241 (Abstract)

Hu Y, Sanders JDH, Kurz SG, Ottobre JS and Day ML (1990) In vitro prostaglandin production by bovine corpora lutea destined to be normal or short-lived Biology of Reproduction 42 801-807

Inskeep EK and Butcher RL (1966) Local component of utero-ovarian relationships in the ewe Journal of Animal Science 25 1164-1168

Lemaster JW, Seals RC, Hopkins FM and Schrick FN (1999) Effects of administration of oxytocin on embryonic survival in progestogen supplemented cattle Prostaglandins 57 259-268

Moor RM and Rowson LEA (1966) Local maintenance of the corpus luteum in sheep with embryos transferred to various isolated portions of the uterus Journal of Reproduction and Fertility 12 539-550

Ramirez-Godinez JA, Kiracofe GH, Carnahan DL, Spire MF, Beeman KB, Stevenson JS and Schalles JJ (1982) Evidence for ovulation and fertilization in beef cows with short estrous cycles Theriogenology 17 409-414

Rowson LEA and Moor RM (1966) Development of the sheep conceptus during the first fourteen days Journal of Anatomy $\mathbf{1 0 0} 777-785$

SAS (1995) SAS User's Guide: Statistics Statistical Analysis System Institute, Inc., Cary, NC

Sayre BL, Taft R, Inskeep EK and Killefer J (2000) Increased expression of insulin-like growth factor binding protein-1 during induced regression of bovine corpora lutea Biology of Reproduction 63 21-29

Schrick FN and Inskeep EK (1993) Determination of early pregnancy in ewes utilizing transrectal ultrasonography Theriogenology 40 295-306

Seals RC, Lemaster JW, Hopkins FM and Schrick FN (1998) Effects of elevated concentrations of prostaglandin $F_{2 \alpha}$ on pregnancy rates in progestogen supplemented cattle Prostaglandins and other Lipid Mediators 56 377-389

Tsai S and Wiltbank MC (1997) Prostaglandin $F_{2 \alpha}$ induces PGHS-2 in the ovine corpus luteum Biology of Reproduction 57 1016-1022

Tsai S and Wiltbank MC (1998) Prostaglandin $F_{2 \alpha}$ regulates distinct physiological changes in early and mid-cycle bovine corpora lutea Biology of Reproduction 58 346-352

Weems CW, Weems YS, Lee CN and Vincent DL (1989) Progesterone in uterine and arterial tissue and in jugular and uterine venous plasma of sheep Biology of Reproduction 41 1-6

Wiltbank JN, Hawk HW, Kidder HE, Black WG, Ulberg LC and Casida LE (1956) Effect of progesterone therapy on embryo survival in cows of lowered fertility Journal of Dairy Science 39 456-461

Received 1 June 2001.

First decision 6 August 2001.

Accepted 28 August 2001. 